\title{
Brain Tumor Initiating Cell Vaccine
}

National Cancer Institute

\section{Source}

National Cancer Institute. Brain Tumor Initiating Cell Vaccine. NCI Thesaurus. Code C97666.

A cell-based cancer vaccine comprised of brain tumor initiating cells (BTICs), with potential immunostimulating and antineoplastic activity. BIT Cs are from the glioblastoma multiforme (GBM) cell line GBM- 6 and contain glioma stem-like cell-associated antigens. Upon administration, the BITC vaccine may stimulate a specific anti-tumoral cytotoxic Tlymphocyte $(C T L)$ response against brain tumor cancer cells and brain tumor stem like cells, resulting in tumor cell lysis. BITC have unique antigenicity and have the ability to self-renew; vaccination against BITC antigens may kill these cells and may prevent tumor recurrences. 